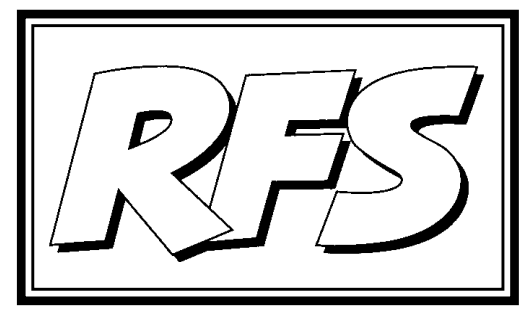

Revista de Fomento Social, 60 (2005), 11-38

\title{
Desarrollo económico y social: teorías, propuestas, responsabilidades
}

\section{Consejo de Redacción}

(Palabras Clave: Economía mundial, Pobreza, Desarkollo, Ética global)

(KEY WORDS: WORLD ECONOMY, POVERTY, DEVELOPMENT, GLOBAL ETHICS)

\section{Presentación}

En el año 2000, en la cumbre del Milenio convocada por Naciones Unidas, los dirigentes de 189 países dieron su visto bueno a los llamados Objetivos del Milenio ${ }^{l}$. Entre dichos objetivos está el de reducir a la mitad, para el año

1 No es éste el lugar de detenernos en el análisis detallado de las metas. Sobre los objetivos, las metas y el grado de avance de la consecución de los mismos, se puede consultar alguna de las innumerables fuentes disponibles; véase la página Web de la ONU: http://www.un.org/ spanish/millenniumgoals/ 
2015, la pobreza extrema a escala mundial ${ }^{2}$. A pesar de las dificultades que se están encontrando para alcanzarlos, se está logrando una difusión y una utilización masiva de estas metas como foco orientador de todas las estrategias de desarrollo puestas en marcha desde entonces, tanto por los propios países en desarrollo, como por los organismos internacionales, los países donantes y las propias organizaciones no gubernamentales del Norte y del Sur. Por ello, existe una fundada esperanza de que todo ello favorezca el debate y aumente la sensibilización acerca de la necesidad de avanzar hacia la reducción de la pobreza y de consensuar prioridades e incluso "estilos" a la hora de fomentar el progreso económico y social de los países menos desarrollados.

El Consejo de Redacción de nuestra Revista ha propuesto en los últimos años en varias ocasiones sus reflexiones acerca de los temas relacionados con la globalización, la pobreza, el desarrollo y la cooperación al desarrollo ${ }^{3}$. Sin embargo, no hemos ofrecido una reflexión de conjunto sobre nuestra concepción del desarrollo, en el marco de la actual situación mundial, marcada por la presencia masiva de la pobreza y de la desigualdad.

Hemos pensando que, a la luz precisamente de dichos Objetivos del Milenio y en el contexto descrito ${ }^{4}$, las reflexiones que ofrecemos en este editorial pueden resultaroportunas como contribución al debate abierto. Analizaremos, en lo que

2 Se trata, como saben nuestros lectores, de 8 objetivos que, a su vez, se desglosan en 18 metas más concretas con sus correspondientes indicadores: 1. Erradicar la pobreza extrema y el hambre. 2. Lograr la enseñanza primaria universal. 3. Promover la igualdad de géneros y la autonomía de la mujer. 4. Reducir la mortalidad infantil. 5. Mejorar la salud materna. 6. Combatir el VIH/SIDA, el paludismo y otras enfermedades. 7. Garantizar la sostenibilidad del medio ambiente. 8. Fomentar una asociación mundial para el desarrollo.

3 "Las dos batallas del 0,7\%: solidaridad y desarrollo" (octubre-diciembre 1994, $\mathrm{n}^{\mathrm{O}}$ 196); "El reto de la pobreza" (julio-septiembre 1996, $\mathrm{n}^{\circ} 203$ ); "Globalización integradora vs. globalización excluyente" (abril-junio 2000, n⿳ 218); "De Río (1992) a Johannesburgo (2002): ¿éxito o fracaso de la Cumbre Mundial sobre el Desarrollo Sostenible?" (julio-septiembre 2002, n⿳⼈ㅡㄴ 227).

4 En España, la reciente promulgación por el gobierno del Plan Director de la Cooperación Española 2005-2008 resalta de manera muy significativa el carácter programático de estos objetivos: "En los últimos años se ha conseguido construir un importante consenso a nivel internacional sobre cómo reducir la pobreza en el mundo. Un compromiso que comparten las organizaciones del sistema de Naciones Unidas, la OCDE y las instituciones de Bretton Woods -el Banco Mundial y el FMI-, pero también, y lo que es más importante, un creciente número de países tanto del Norte como del Sur. Este consenso está basado en la Declaración del Milenio que sintetiza, aunque no recoge en su totalidad, los diferentes compromisos adoptados en las sucesivas Cumbres Mundiales que las Naciones Unidas fueron celebrando en la década de los 90." (capítulo 1, apartado 2). 
sigue, las principales teorías que se han elaborado para explicar el desarrollo; presentaremos luego un decálogo con orientaciones sobre cómo concebimos nosotros el auténtico desarrollo; insistiremos, por último, en las responsabilidades que tiene el Norte en los problemas del subdesarrollo del Sur.

\section{Presupuesto: hacia una teoría "ecuménica" del desarrollo}

La exposición detallada y el debate en torno a las diferentes teorías del desarrollo que se han propugnado a partir de la segunda guerra mundial ocuparían una extensión fuera de lugar en el presente texto, pero una referencia a las mismas y un posicionamiento relativo parecen necesarios ${ }^{5}$.

Hoy se habla mucho de fracaso del desarrollo y, por ende, de fracaso de las teorías del desarrollo. Pero el que las teorías hayan fracasado no quiere decir que no sean importantes. Al final, como dice J.M. Keynes en un famoso texto:

“...las ideas de los economistas y de los filósofos políticos, tanto cuando son correctas como cuando están equivocadas, son más poderosas de lo que comúnmente se cree. En realidad el mundo está gobernado por poco más que esto. Los hombres prácticos, que se creen exentos por completo de cualquier influencia intelectual, son generalmente esclavos de algún economista difunto... Estoy seguro de que el poder de los intereses creados se exagera mucho comparado con la intrusión gradual de las ideas... Pero, tarde o temprano, son las ideas y no los intereses creados las que presentan peligros, tanto para mal como para bien"6.

\section{1.- Una sistematización de las teorías del desarrollo}

La reflexión teórica sobre el desarrollo a escala mundial, en estricto rigor, no comienza en realidad hasta después de la Segunda Guerra Mundial. Antes, sin duda, se encuentran planteamientos seminales en los clásicos de la economía. El cuadro siguiente es un intento de síntesis de las principales familias teóricas.

5 Remitimos a los lectores a un par de manuales excelentes en castellano: P. Bustelo (1998), Teorías contemporáneas del desarrollo económico, Madrid, Síntesis, 303 pp.; A. L HIDALGO CAPITÁn (1998), El pensamiento económico sobre desarrollo. De los Mercantilistas al PNUD. Huelva, Publicaciones Universidad de Huelva, 255 pp.

6 J. M. Keynes (1987), Teoría general de la ocupación, el interés y el dinero. México-Madrid-Buenos Aires, Fondo de Cultura Económica. 13ª impresión, p. 337 (últimas palabras del libro) (original: 1936). 


\section{Estructura de la Economía del Desarrollo y el pensamiento económico sobre desarrollo - Un esquema simplificado de análisis}

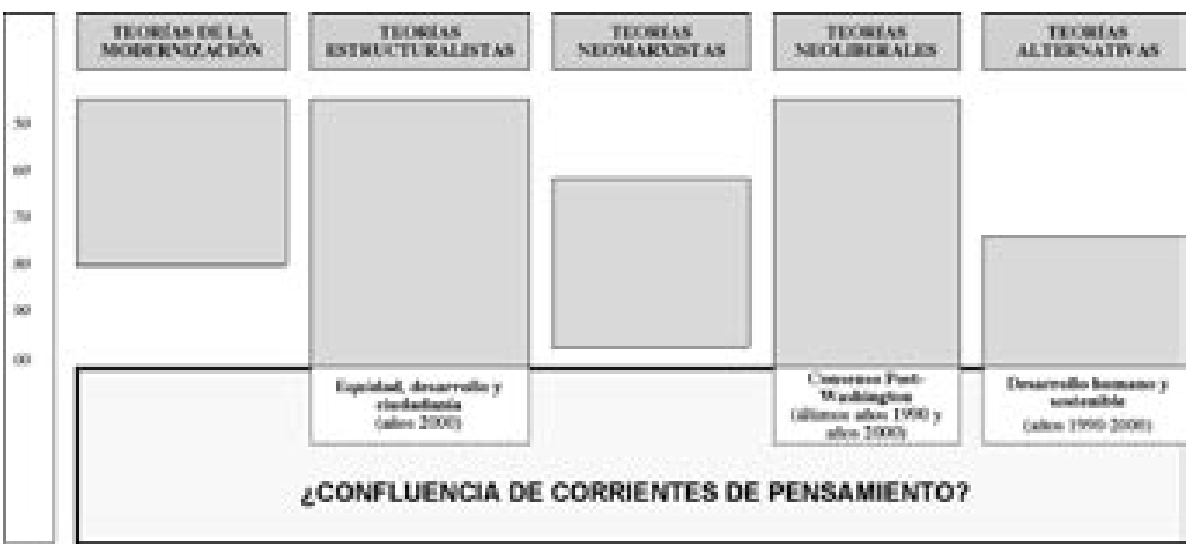

Fuente: A. L. HidAlgo CAPITÁN (1998), op. cit. p. 232. y G. FeRRERO y dE LOMA-OSORIO (2003), De los proyectos de cooperación a los procesos de desarrollo, Valencia, Universidad Politécnica de Valencia, p. 72. Para no abrumar a nuestros lectores, simplificamos al máximo el cuadro, eliminando las alusiones a las numerosas teorías incluidas dentro de cada familia.

El esquema anterior permite observar, muy expresivamente, que de las cinco grandes familias teóricas en que los autores han agrupado a los numerosos estudiosos que han abordado el tema del desarrollo económico, después de la Segunda Guerra Mundial, dos se interrumpen (al menos pasan a ser muy minoritarias) antes de los años 90 del siglo XX: la familia de teorías llamadas "de la modernización" (entre ellas se encuentran aportaciones tan populares como la teoría de las etapas de Rostow, entre otras) y las teorías "neomarxistas". Otras tres ramas, en cambio, sobreviven, e incluso gozan de buena salud en el mercado de las ideas y de las políticas económicas, y son las que alimentan la polémica teórica en la actualidad: las "teorías neoliberales", las "teorías neoestructuralistas" y las "teorías alternativas"7. A efectos puramente didácticos, nosotros proponemos agrupar las "teorías de la modernización" y las "teorías neoliberales" dentro de un bloque que denominamos, para enten-

7 Preferimos usar el plural, dado que se trata de una agrupación de elementos teóricos heterogéneos, que siempre tiene mucho de convencional. 
dernos, "teorías ortodoxas"8. A su vez, agrupamos a las "teorías neomarxistas" y a las "estructuralistas", dentro de una familia más amplia, que denominamos "teorías heterodoxas". Y mantenemos el calificativo de "teorías alternativas" para las así denominadas por los autores en que basamos nuestro resumen'.

\section{2.- Las tres principales familias teóricas "supervivientes"}

Aunque seguramente muchos de los autores implicados en eso que hemos llamado "familias" de teorías se sentirían incómodos en la clasificación propuesta, creemos que tiene su utilidad a efectos didácticos. Con esta intención sintetizaremos los principales rasgos de cada una.

a) La familia de las teorías ortodoxas: de la teoría de la modernización al neoliberalismo

Estas teorías identifican desarrollo con desarrollo económico, y éste último con mero crecimiento económico. El objetivo del desarrollo consiste en aumentar el PNB per cápita. Por lo demás, consideran el subdesarrollo como un problema de atraso relativo: por tanto, para salir de él basta con recorrer las etapas que los países industrializados han ido recorriendo (Rostow podría ser un autor significativo al respecto ${ }^{10}$ ). La clave del desarrollo se encuentra en la industrialización; por ello se defiende un modelo de sustitución de importaciones. Por otro lado, se requiere una cierta intervención estatal en la planificación del desarrollo.

Los críticos de estas teorías suele achacarles su excesivo énfasis en la acumulación de capital y en la industrialización; su escasa atención a los efectos distributivos de las medidas propugnadas; su proteccionismo y su claro sesgo antiexportador.

8 Entre otros, utilizan esta división en teorías ortodoxas y heterodoxas C. BERzosa - P. Bustelo - J. DE LA IgleSIA (1996), Estructura Económica Mundial, Madrid, Síntesis, pp. 243-276.

9 Se trata, insistimos, de una clasificación didáctica y práctica; se parece mucho, por ejemplo, a la que adoptaba el secretario general de la UNCTAD, RUBENs RICUPERO (1999), "La integración de los países pobres en la economía mundial”, Revista de Fomento Social, n⿳丷. 215, julio-septiembre, pp. 370-371.

10 W. W. Rostow (1973), Las etapas del crecimiento económico, México, Fondo de Cultura Económica (1 $1^{\text {a }}$ ed.: 1960). 
En la actualidad la herencia de esta familia la han recibido los neoliberales, un pensamiento que, sin duda, goza de buena salud en nuestros días. Un buen resumen de este paradigma es el conocido decálogo del Consenso de Washington. La primera formulación del mismo se debe a John Williamson ("Lo que Washington quiere decir cuando se refiere a reformas de las políticas económicas") y data de 1990, aunque su autor la había publicado con anterioridad. El escrito concreta diez temas de política económica, en los cuales, según el autor, "Washington" está de acuerdo. "Washington" significa el complejo político-económico-intelectual integrado por los organismos internacionales (Fondo Monetario Internacional, Banco Mundial), el Congreso de los EEUU, la Reserva Federal, los altos cargos de la Administración estadounidense y algunos grupos de expertos ${ }^{11}$. Este decálogo se puede resumir en tres grandes principios:

- Políticas macroeconómicas sólidas (baja inflación, déficits públicos mínimos y equilibrios en las cuentas exteriores).

- Apertura económica de los países siguiendo la vía de la liberalización comercial y financiera.

- Mayor protagonismo para el mercado y reducción correlativa del Estado, a través de la privatización y de la desregulación, hasta dejarlo limitado a sus tareas esenciales.

Es de justicia decir que el propio Williamson ${ }^{12}$ ha matizado y rectificado notablemente el alcance y la universalidad de estas orientaciones: reconoce su sesgo neoliberal, admite que son incompletas y deplora que hayan sido utilizadas de forma sectaria por los fundamentalistas del mercado.

b) La familia de las teorías heterodoxas: de los neomarxistas a los neoestructuralistas

El pensamiento heterodoxo abarca muchas corrientes teóricas, que coinciden en cuestionar el pensamiento económico convencional al que se califica de

11 J. F. MÀrIA (2000), "El 'Consenso de Washington’ ¿Paradigma económico del capitalismo triunfante?", Revista de Fomento Social, nº 217, enero-marzo, p. 32.

12 Entre otros lugares, en un artículo publicado en Finanzas y Desarrollo (publicación trimestral del Fondo Monetario Internacional), septiembre 2003, pp. 10 ss.: “...este programa estaba originalmente dirigido a la América Latina de 1989, pero se vuelve grotesco cuando se lo interpreta como un programa para todos los países en cualquier época" y otras afirmaciones parecidas criticando la utilización dogmática del famoso decálogo. 
"ortodoxo". Simplificando un poco, se puede decir que las teorías heterodoxas coinciden en que el subdesarrollo no es un estado transitorio o una etapa en un proceso, sino la consecuencia de unas estructuras económicas internacionales $y$ de sus efectos sobre la propia estructura de los países más atrasados. Nos fijaremos sólo en algunos de sus principales exponentes: los neomarxistas, el estructuralismo de la CEPAL (Comisión Económica para América Latina, de Naciones Unidas) y los neoestructuralistas.

Para resumir lo esencial de las teorías neomarxistas habría que mencionar al menos estos puntos:

- El subdesarrollo se debe a la continua extracción del excedente por las economías capitalistas avanzadas.

- El desarrollo se conseguiría con una reinversión nacional de ese excedente, que permitiera un aumento de la renta que posteriormente sería redistribuida de forma equitativa.

- Las clases dominantes de la periferia no están interesadas en desarrollar un capitalismo productivo.

- El desarrollo económico pleno sólo puede darse con un cambio político radical.

Independientemente del desprestigio que implicó para los planteamientos inspirados en el marxismo el desmoronamiento del bloque del socialismo real, estas teorías han sido criticadas por un cierto simplismo. Seguramente -entre otras cosas-no explicitaron suficientemente la dimensión interna o endógena del subdesarrollo, insistiendo de forma unilateral en los aspectos relacionados con las indudables inequidades de las relaciones económicas internacionales.

Un planteamiento, en cierto modo pionero, de las teorías heterodoxas proviene del Informe de 1949 de la CEPAL: El desarrollo económico de América Latina y algunos de sus principales problemas. Este informe se basa en el sistema centro-periferia: los países del Norte (con los grandes poderes del "gran" capital, las multinacionales y los grupos a ellas ligados) frente a los países del Sur y a las clases sociales menos favorecidas de los países del Norte. En este sistema se analiza, desde una perspectiva histórica, un conjunto de problemas económicos y sociales. Sus planteamientos pueden resumirse en las siguientes proposiciones:

- El centro se caracteriza al mismo tiempo por la homogeneidad y la diversificación. La periferia tiene, en cambio, una estructura heterogénea 
y especializada. En las periferias coexisten dos agriculturas: una de exportación (productiva) y otra de subsistencia.

- Desarrollo y subdesarrollo forman un único sistema mundial, donde el centro se especializa en produciry exportar manufacturas, mientras que la periferia, al menos tradicionalmente, produce y exporta materias primas, al tiempo que consume parte de los productos elaborados en el Norte.

- Las relaciones económicas reproducen las disparidades. El libre comercio acentúa las desigualdades internacionales. El informe critica el principio del beneficio mutuo basado en la teoría de las ventajas comparativas de David Ricardo.

- Los resultados económicos del progreso técnico se concentran en el centro, mediante dos mecanismos complementarios: a) la fuerza política y organizativa del centro impide que el aumento de la productividad en el Norte reduzca los precios de las manufacturas; b) el aumento del precio de las importaciones y la caída del precio de las materias primas (deterioro de los términos del intercambio) impide el aumento de la productividad laboral en los países del Sur.

Entre los muchos y cualificados herederos y continuadores de estas corrientes hoy destacan los neoestructuralistas ${ }^{13}$, una especie de revitalización del pensamiento de la CEPAL. Parten de un fuerte rechazo del consenso de Washington, para lo que aducen tres motivos fundamentales: a) su pretensión generalizadora, que ignora la diversidad de la realidad a considerar; b) el alto coste social de las políticas de estabilización y ajuste, que contrasta con sus mediocres resultados; c) su insistencia en que hay que empezar por la estabilización y el ajuste, dejando "para más adelante" otras tareas, como por ejemplo la lucha contra la pobreza o los cambios estructurales y procesos de democratización.

Las contrapropuestas neoestructuralistas van en las líneas siguientes: a) las medidas de estabilización deben ser aplicadas con suma cautela; b) es preciso considerar los inconvenientes de medidas de carácter generalizado (liberalización externa, privatización, flexibilidad laboral, desregulación financiera...); c) hay que recuperar al Estado como actor esencial, tanto en acciones funcionales (capital humano y físico) como selectivas (sectores).

13 Cfr. una explicación muy clara de esta tendencia en: I. CAMACHO LARAÑA (1992), "América Latina tras la década perdida”, Revista de Fomento Social, n 188, octubre-diciembre, pp. 482 ss. 
c) La familia de las teorías alternativas: de Todaro al Programa de Naciones Unidas para el Desarrollo (PNUD)

Aunque existen precedentes importantes, destacamos en este grupo las aportaciones pioneras de MICHAEL TODARO quien, en su famoso e insustituible manual, define el desarrollo como:

“...un proceso multidimensional, compuesto por grandes transformaciones de las estructuras sociales, de las actitudes de la gente y de las instituciones nacionales, así como por la aceleración del crecimiento económico, la reducción de la desigualdad y la erradicación de la pobreza absoluta"14.

Según Todaro, tres son los valores centrales del desarrollo:

- Sustento vital: satisfacción de las necesidades básicas.

- Autoestima: ser persona.

- Libertad y no servidumbre: poder elegir.

Cuando faltan uno o más de estos valores, se produce el círculo vicioso del subdesarrollo; en efecto, sus carencias respectivas se retroalimentan mutuamente.

Estas ideas de Todaro enlazan con el concepto de desarrollo humano, elaborado a través de los Informes anuales de Desarrollo Humano del PNUD, que se han venido publicando a partir de 1990. Este nuevo concepto, verdaderamente alternativo, se apoya en la solidez de sus bases teóricas (esencialmente debidas a los trabajos de Amartya Sen, Premio Nobel de Economía en 1998) y al hecho de haberse plasmado en algunos indicadores multidimensionales (entre los que destaca el famoso Índice de Desarrollo Humano).

Sen aporta a la Teoría del Desarrollo su comprensión del bienestar: qué es el bienestar y quién es el sujeto del bienestar. Para Sen, el sujeto del bienestar es el ser humano y en función de aquél debe definirse éste. Un mayor bienestar humano exige terminar con la pobreza, la ignorancia, la enfermedad y la desigualdad de oportunidades. La apertura económica contribuye al desarrollo, pero no basta para aumentar el bienestar si no se toman medidas en el campo de la educación y la salud. En último término, el objetivo básico del desarrollo consiste en ampliar la capacidad de las personas. Con estos presupuestos resulta fácil cuestionar la forma de

14 M. P. Todaro (1988), El desarrollo económico del Tercer Mundo, Madrid, Alianza, pp. 120-121. 
entender $y$, por ende, de medir el bienestar que ha venido manejando la Teoría del Desarrollo ${ }^{15}$.

Ya desde el Informe de 1992, inspirado en las ideas de Amartya Sen ${ }^{16}$ y de Mahbud Ul Acq, el PNUD definió de esta forma el desarrollo humano:

"Proceso de ampliar la gama de opciones de las personas, brindándoles mayores oportunidades de educación, atención médica, ingreso y empleo, y abarcando el espectro total de opciones humanas, desde un entorno físico en buenas condiciones hasta libertades económicas y políticas"17.

Este nuevo enfoque implica una revisión de los indicadores clásicos, tan queridos de las familias del primer grupo pero también utilizados con profusión por las del segundo grupo, tales como el Producto Nacional Bruto (desarrollo equivaldría a crecimiento económico). En efecto, ahora nadie duda ya que el $P N B$ es un instrumento sumamente defectuoso para medir el desarrollo: sólo registra los intercambios monetarios (ignora, por ejemplo, el trabajo en la familia y la comunidad); valora por igual todas las actividades productivas, independientemente de que sus resultados sean positivos o perjudiciales para la sociedad; registra tanto las adicciones como su remedio (comida, aunque sea perjudicial, y las dietas para adelgazar; el consumo de alcohol y las terapias para superar el alcoholismo); considera que los recursos naturales son gratuitos; no asigna valor al tiempo libre; deja de lado la libertad humana; no incorpora el valor de los bienes públicos. Sería muy difícil elaborar un índice capaz de reflejar todas estas cosas... Pero, ¿no es posible, al menos, mejorar la medición del desarrollo?

El Índice de Desarrollo Humano, que pretende recoger estos enfoques, conjuga tres variables: a) la longevidad (medida por la esperanza de vida al nacer); $b$ ) el nivel educativo (medido por una combinación de tasa de alfabetización de adultos y la tasa de matriculación combinada de educación primaria, secundaria y superior); c) el nivel de vida (medido por el PIB per cápita a igualdad de poder adquisitivo).

15 Véase por ejemplo: F. EQuizA, “Amartya Sen y sus aportaciones a la Teoría del Desarrollo: Algunas reflexiones”, en Desarrollo Humano e Institucional en América Latina, Instituto Internacional de Gobernanza de Cataluña, $n^{\circ} 23$. (http://www.iigov.org/dhial/). Texto consultado el 30 de marzo de 2005.

16 Alguna de sus obras fundamentales en castellano: Nuevo examen de la desigualdad, Alianza, 1995; Sobre ética y economía, Alianza, 1997; Bienestar, justicia y mercado, Paidos, 1997; Sobre la desigualdad económica, Folio, 1997; Elección colectiva y bienestar social, Alianza, 1976; Desarrollo y libertad, Planeta 2000.

17 PNUD (1992), Informe sobre desarrollo humano 1992, PNUD y Mundi Prensa. p. 18. 
Complementario de este concepto de desarrollo humano es el de desarrollo sostenible, que se difunde en la escena mundial a partir de una serie de informes y documentos que giran todos en torno a una idea fundamental, no por obvia fácil de asimilar: "no es posible lograr un crecimiento infinito con recursos finitos". Tal idea fue popularizada a escala mundial por el muy famoso primer Informe al Club de Roma ${ }^{18}$, que abrió un debate universal sobre la imposibilidad de mantener el ritmo de aumento del consumo de recursos no renovables y de generación de contaminación.

Años más tarde, fue el Informe Brundtland ${ }^{19}$, de la Comisión Mundial del Medio Ambiente y el Desarrollo de la ONU, el que lanzó el término desarrollo sostenible, que sirvió de base conceptual de la Cumbre de Río en 1992. El desarrollo sostenible fue definido como "aquél que satisface las necesidades del presente sin limitar el potencial para satisfacer las necesidades de las generaciones futuras". La Cumbre de Río está constatando con este concepto el agotamiento de un modelo de desarrollo, generador de injusticia y malestar social y causante de una intensa degradación ecológica. La famosa Agenda 21 propone algunos cambios en los modos de producción y consumo coherentes con esta constatación.

Pero también esta tercera familia de teorías, a pesar de lo seductor de sus propuestas conceptuales y cuantitativas, ha sido blanco de críticas. En particular, se les ha acusado de carecer del desarrollo teórico de las corrientes anteriores, de no proponer un modelo integral de desarrollo y quedarse en aspectos parciales del mismo, incluso de ser más una aproximación voluntarista e incluso utópica que un verdadero paradigma del desarrollo.

\subsection{Hacia una cierta convergencia en las teorías del desarrollo}

El panorama de las teorías, que hemos querido resumir, parece obligarnos a hacer una opción: ¿con cuâl de ellas quedarnos? No creemos, sin embargo, que sea preciso una opción excluyente. Con muchos otros autores pensamos que se abre camino una "nueva economía del desarrollo" que puede y debe

18 Meadows y Meadows (1972). Los límites del crecimiento. México, Fondo de Cultura Económica, 1972.

19 G. H. Brundtland (dir.) (1989), Nuestro futuro común, Madrid, Alianza (original: 1987) Cfr. un análisis sobre el concepto de desarrollo sostenible en J. J. Romero Rodríguez (1993), "Los límites de crecimiento, después de Río 92. ¿Más allá del desarrollo sostenible?”, Revista de Fomento Social, nº 189, enero-marzo 1993, pp. 11-40. 
incorporar-sin unilateralismo ni posiciones parciales-los aspectos rescatables de las diferentes familias teóricas. Es hora de superar la dialéctica de confrontación que ha marcado la evolución de los diferentes paradigmas, dificultando todo entendimiento y consenso entre ellas. Creemos, con Ricupero, que hay que evitar hacer una guerra de religión de estas batallas teóricas:

“...me gustaría insistir en que nadie debería intentar convertir este debate en una nueva versión de las guerras de religión. Nadie niega, por ejemplo, que muchas de las cosas del consenso de Washington siguen siendo válidas e imperativas. El mismo profesor Stiglitz tituló una de sus conferencias "Más allá del consenso de Washington", y todos nosotros estamos precisamente intentando avanzar más allá de él. Acertadamente Stiglitz afirmó en esa conferencia que algunas de las prescripciones del consenso de Washington son necesarias pero no suficientes por sí mismas, y que otras políticas no han merecido la misma atención que estas prescripciones... Estamos intentando mirar más allá del consenso de Washington con el fin de alcanzar un consenso común que pueda ser ampliamente compartido, un consenso basado en la necesidad de equilibrio y de un sentido de la proporción, que no vuelva a abrir las viejas batallas ideológicas de los años 70 o de los 80, y que se preocupe, en cambio, de integrar de forma más plena la complejidad y la diversidad de las condiciones que influyen en el desarrollo. En este sentido, queda todavía mucho que hacer para reconciliar extremos aparentemente contradictorios, tales como el papel del Estado y el mercado, la estabilidad de precios y el crecimiento económico, la flexibilidad del mercado de trabajo y la seguridad en el empleo, la integración en la economía mundial y la construcción de una base industrial nacional. Todos estos aspectos han sido presentados con frecuencia como posiciones antagónicas, mutuamente excluyentes, pero la búsqueda de alternativas que está teniendo lugar en la actualidad está inspirada justamente por la necesidad de adoptar un enfoque multidisciplinar y de ver en qué medida podemos alcanzar estos objetivos que se refuerzan mutuamente y son complementarios" 20

De alguna manera, el debate ideológico se ha moderado. Con diferencias de énfasis, se van produciendo ciertos consensos: que el desarrollo no será posible mientras persistan grandes desajustes macroeconómicos; que el problema de la mayoría de los países empobrecidos no es que haya demasiado Estado, ... sino que en la práctica no hay Estado, nunca lo ha habido y esa falta de institucionalidad básica es una parte fundamental del problema; que la pobreza no se resolverá automáticamente con el crecimiento si no se ataca de raíz y directamente mediante políticas sociales adecuadas.

Esta postura de relativa convergencia podríamos expresarla de forma más sistemática recogiendo las contribuciones más aprovechables de cada familia y estableciendo entre ellas un orden de prioridades ético-políticas:

20 R. RICUPERO (1999), pp. 371-372. 
- De las corrientes "alternativas" hay que retener el concepto mismo de desarrollo, que expresa cuál es el objetivo último de toda estrategia: el desarrollo como proceso centrado en la ampliación de las oportunidades de opción del ser humano en el presente y en el futuro. Esta visión del desarrollo pone el énfasis en la calidad de vida y presta especial atención a la educación, a la esperanza de vida, a la calidad del sistema de salud, a la erradicación de la pobreza, a la equidad de género, al respeto de los derechos humanos, a la vida en un entorno (medio ambiente) saludable y a la satisfacción de las necesidades presentes y futuras. Es también un enfoque que intenta construir la sociedad desde sus bases mismas, edificando sobre organizaciones nacidas en la comunidad local y en la sociedad civil, con mucha mayor participación. Todo esto responde a las cuestiones más fundamentales, que son de inequívoco carácter ético: ¿qué tipo de persona queremos favorecer con el desarrollo? ¿qué tipo de sociedad queremos construir como marco para el desarrollo de esa persona? Y no deja de ser paradójico que lo que es esencial desde un enfoque ético coincida precisamente con lo que ha sido formulado en época más reciente por los teóricos del desarrollo. Todo lo que viene a continuación tiene carácter instrumental y está al servicio de estos objetivos de un desarrollo que merezca el nombre de tal.

- De los planteamientos "neoestructuralistas" rescatamos sobre todo el papel esencial del Estado en el desarrollo, la necesidad de fortalecer la institucionalidad y la gobernabilidad y de potenciar el capital social. $E l$ logro de un desarrollo humano y sostenible requiere mucho más que la "mano invisible" del mercado, la cual es demasiado corta de vista para garantizar un futuro adecuado para la humanidad. Un sistema eficiente de mercados competitivos es importante, pero debe ser complementado por estrategias cooperativas y por un marco de regulación. Si las primeras son de iniciativa social, ésta última es tarea propia del Estado y del poder legítimamente constituido.

- De los enfoques "neoliberales", especialmente en formulaciones del Consenso de Washington, aceptamos la necesidad de la estabilización: con alta inflación o elevados déficits fiscales no es posible el desarrollo... Pero no a cualquier precio: qué precio hay que pagar, quién ha de pagarlo, cómo minimizar los costes del ajuste, etc., todas ésas no son cuestiones banales. No hay que demonizar a priori algunos de los postulados neoliberales, pero tampoco puede ignorarse que las políticas de ajuste aplicadas recientemente han conseguido, en la mayoría de los casos, éxitos en la 
mejora de los parámetros macroeconómicos, pero han tenido también enormes efectos en el aumento de la pobreza, de la vulnerabilidad y de la desaparición de clase media. Podemos decir, entonces, que la estabilidad macroeconómica es una condición necesaria para el desarrollo, pero dicha estabilidad y la mejora de las variables macro no equivalen sin más a desarrollo y, en muchos casos, hasta son contrarias al mismo.

En todo caso, el desarrollo es un proceso multidimensional que implica: grandes transformaciones de las estructuras sociales, de las actitudes de la gente y de las instituciones nacionales, la aceleración del crecimiento económico, la reducción de la desigualdad y la erradicación de la pobreza absoluta. Y todo ello inspirado por los tres valores centrales ya mencionados: a) sustento vital (capacidad de satisfacer las necesidades básicas); b) autoestima (ser persona); c) libertad y no servidumbre (poder elegir).

$Y$ a todo esto hay que añadir otro elemento esencial: el convencimiento colectivo de que la mejora no sólo es necesaria sino posible. La historia de las últimas décadas muestra que el desencanto y pérdida de ilusión y autoestima de generaciones enteras, después de experiencias continuadas de frustración y hasta de violencia, son un obstáculo que frena poderosamente la dinámica de desarrollo en pueblos enteros.

\section{Diez principios fundamentales del desarrollo}

Si bien es cierto que la evolución reciente de las políticas, a escala global, no permiten ser muy optimistas sobre la aplicación práctica de los criterios ofrecidos, creemos que hay datos para alimentar una cierta esperanza. Apoyamos esta convicción en la ya madura experiencia de 20 años del equipo de ETEA en Investigación, Cooperación y Educación al Desarrollo y en los debates con otros equipos de investigación y acción tanto en España como en América Latina. Desde esa atalaya, se presentan a continuación, bajo la forma de un decálogo, los principios que pensamos deberían impulsar todo trabajo concreto de desarrollo 21 .

21 Aunque este decálogo fue formulado inicialmente pensando en el desarrollo rural, lo hemos reelaborado ampliándolo a todos los ámbitos del desarrollo. Sus orígenes pueden verse en el documento "Bases para un plan de Desarrollo Rural de Nicaragua", elaborado en el marco de la Iniciativa para el Desarrollo Rural de Nicaragua, editado en Nicaragua por la Universidad Centroamericana de Managua y patrocinado por la Agencia Española de Cooperación al Desarrollo (AECI). Véase J. J. ROMERo y G. FERRERo (coords.) (2004), Desarrollo Rural en Nicaragua. Del consenso en los principios a una propuesta para la acción, Bilbao, Desclée de Brouwer. 
3.1. El desarrollo humano como principio de partida. Un desarrollo con equidad en las diferencias

El consenso acerca de lo que se ha dado en llamar desarrollo humano es hoy por hoy prácticamente total al menos en el discurso. Se define, en línea con las propuestas de Sen y del PNUD, como el "proceso de ampliar la gama de opciones de las personas, brindándoles mayores oportunidades de educación, atención médica, ingreso y empleo, y abarcando el espectro total de opciones humanas, desde un entorno físico en buenas condiciones hasta libertades económicas y políticas".

Desde esta óptica, el desarrollo centrado en la persona supone apartarse de una concepción exclusivamente macroeconómica del desarrollo y orientarse hacia el aumento de las oportunidades del ser humano en todas sus dimensiones $^{22}$.

De la consideración de la noción de desarrollo humano, como punto de partida, emerge el concepto de equidad (igualdad de oportunidades dentro de la diversidad) como eje central del concepto de desarrollo. Esta equidad dentro de la diferencia implica, en particular, no sólo el reconocimiento de la equidad de género, si también la participación específica de la mujer en el desarrollo; implica igualmente, no sólo el respeto y potenciación de las diferentes culturas y etnias, sino además la participación de los pueblos indígenas en estos procesos.

3.2. Un desarrollo humano y sostenible: la compatibilidad con la reproducción de los equilibrios de los ecosistemas

El imperativo de un desarrollo que sea sostenible es hoy admitido por todos. Pero la interpretación de su contenido muestras importantes diferencias: la economía ambiental, más cercana al neoliberalismo, se basa en la internalización de costos ambientales y confía en el mercado para garantizarlo: la economía

En el documento original se encontrarán las referencias al numeroso grupo de personas e instituciones que participaron de diversas maneras en la elaboración del texto, entre ellos -en diversas fases y con distinto grado de responsabilidad- algunos profesores de ETEA.

22 Es interesante constatar que "el desarrollo al servicio de la persona", sumamente próximo a lo que el PNUD denomina "desarrollo humano" es un concepto formulado a nivel más general ya en 1965 en la Constitución Pastoral sobre la Iglesia en el mundo moderno "Gaudium et spes" del concilio Vaticano II, y ulteriormente elaborado en 1967 en la encíclica sobre el desarrollo de los pueblos "Populorum Progressio" de Pablo VI. 
ecológica y el ecodesarrollo llegan hasta a poner en cuestión los fundamentos de los modelos de consumo y producción actuales y niegan la capacidad del mercado para corregir eficientemente el problema. Nosotros consideramos necesaria una cierta síntesis de ambas corrientes.

Por un lado, la progresiva internalización de costes (protección del medioambiente penalizando a quien contamina mediante tasas, impuestos o multas, $y$ dejando que el mercado premie a quien produce "limpio") es un camino positivo pero insuficiente. Por otro lado, si se quiere un desarrollo que sea sostenible, es necesario cuestionar los modelos de producción y consumo actuales, que fomentan el despilfarro de recursos y generan efectos negativos medioambientales considerables, y buscar alternativas que, en la mayor parte de las ocasiones, existen: ¿no hay sistemas de producción que generan externalidades ambientales positivas en coherencia con la racionalidad individual del productor? ¿no deberían ser potenciados e incentivados estos sistemas?

La apuesta por un desarrollo sostenible, lejos de ser interpretada como un freno al desarrollo, debe ser contemplada como una oportunidad que pueda articular una estrategia de desarrollo. El desarrollo sostenible sería entonces - así lo afirma en el Informe de Desarrollo Humano 1998- el marco para que los países del Sur configuraran un modelo de desarrollo que no siguiera las mismas etapas que han seguido los países industrializados, etapas tantas veces extraordinariamente depredadoras de recursos y destructoras del medio ambiente.

En cualquier caso es necesario superar el enfrentamiento ficticio que se plantea en algunas ocasiones en determinados foros y por determinados actores entre "conservación medioambiental" y "satisfacción de las necesidades humanas". No puede llamarse desarrollo sostenible a aquél que no garantiza la satisfacción de las necesidades básicas y mantiene la pobreza, ni es admisible un desarrollo humano hoy que ponga en peligro el desarrollo humano futuro. Es necesario, en este sentido, enfatizar que los grandes problemas de depredación medioambiental están mucho más asociados a la acumulación de capital y su manejo extensivo que a la satisfacción de las necesidades básicas.

En resumen, los países en desarrollo tienen que avanzar en la puesta a punto de medidas que permitan internalizar los costes ambientales; pero se trata además de postular un modelo de desarrollo sostenible que, desde la base, promueva nuevos modos de consumo y producción limpios, conservadores y regeneradores del medio ambiente, viendo en todo ello un camino real y viable a largo plazo para la superación de la pobreza. No cabe duda que ello supone 
un reto difícil a todos los niveles y que exige más creatividad e innovación.

Más aún, "a fin de alcanzar el desarrollo sostenible, la protección del medio ambiente deberá constituir parte integrante del proceso de desarrollo y no podrá considerarse en forma aislada"23. Ello implica un tratamiento transversal del medioambiente, considerándolo en todas las fases de la planificación del desarrollo y a todos los niveles (algo parecido a lo que se dice de la perspectiva del género).

\subsection{La dimensión espacial de las diferencias: la geografía humana}

La noción de desarrollo humano sostenible asume que el reconocimiento y respeto de la diversidad cultural, étnica, histórica y de género constituye uno de lo activos y valores principales de las sociedades; además asocia lo social y cultural a lo medioambiental, lo ecológico y a los espacios locales y, por tanto, introduce la consideración de la diversidad y la diferencia a los territorios. Ello nos lleva a subrayar ahora la importancia de la diversidad asociada a los territorios.

En efecto, una de la fuentes de diferencia más irreductible entre los seres humanos radica en la variedad de ecosistemas en los cuales viven. Éste es el centro de interés de la geografía humana, que enseña que "todo paisaje es producto de la actividad pasada y presente de sus habitantes"; sin embargo hay que añadir que "estas variables naturales condicionan, sin nunca determinar, las variables sociales" (cf. Informe del PNUD de 1998).

Este planteamiento encuentra un instrumento privilegiado de aproximación al desarrollo territorial en una regionalización socio-agro-ecológica que "parte del principio que no se puede entender a los actores de los diversos territorios y a sus instituciones fuera del medio en el cual se han desarrollado y se encuentran en la actualidad". Pero esto no debe ser interpretado en el sentido de un estricto determinismo natural sobre las formas económicas y de organización social, sino como una vía para comprender la simbiosis entre diferencias sociales y diferencias naturales.

Naturalmente a este enfoque se oponen las acciones y políticas homogeneizadoras, que ignoran las diferencias y se niegan a considerar a éstas como un instrumento para lograr la equidad.

23 Principio 4 de la Agenda 21 de la Cumbre de Río. 


\subsection{La lucha contra la pobreza en el marco del desarrollo}

La pobreza, no sólo es éticamente inaceptable, sino que hace insostenible el desarrollo desde el punto de vista medioambiental, económico y social. Está más que comprobado que la desigualdad en la distribución del ingreso o la existencia de un dualismo al estilo del que existe en muchos países en desarrollo (pocos ricos, muchos pobres, ausencia de clase media) frenan el crecimiento económico y el desarrollo de un país. Por otro lado, una mala distribución del ingreso genera baja demanda de bienes necesarios, en su mayoría de producción nacional, orientando la oferta a productos de lujo, generalmente de importación, que están al alcance de unos pocos.

Ahora bien, las políticas de reducción de la pobreza sólo tienen sentido en el contexto de un verdadero plan de desarrollo. En caso contrario, generan dinámicas asistenciales en los territorios y en la gente, que estrangulan las posibilidades reales de desarrollo humano; incluso erosionan el capital social local.

Si la lucha contra la pobreza es un componente imprescindible en las estrategias integrales de desarrollo, las acciones o programas compensatorios o asistenciales deben ser planteados y manejados con extremo cuidado, y aplicados exclusivamente "a los pobres estructurales atrapados en la pobreza que necesitan transferencias permanentes de ingresos para superar la línea de pobreza y para los hogares en pobreza transitoria que necesitan acceso a redes de seguridad para evitar la descapitalización de los activos productivos y para evitarajustes irreversibles frente a situaciones extremas". Estos programas asistenciales deben, pues, diferenciarse, explícitamente y con claridad, de los programas de desarrollo para evitar distorsiones que fueron frecuentes en el pasado: populismo, clientelismo político, insostenibilidad financiera, etc.

A estas estrategias de reducción de la pobreza, orientadas a los estratos en extrema pobreza y siempre combinadas con políticas de desarrollo, ha de unirse otra estrategia complementaria: la creación y consolidación de una clase media, tan decisiva por muchos conceptos. Ella es importante tanto desde el punto de vista de la demanda potencial como desde el punto de vista de su potencial de desarrollo; pero además ella es la principal protagonista de la acumulación de capital (y sabemos que su reproducción ampliada tiene mayor capacidad de generar impactos positivos para los intereses colectivos). Sólo queda añadir que la población meta más adecuada para conseguir estos objetivos será la de los sectores pobres con más potencial de desarrollo. 
En cualquier caso, la lucha contra la pobreza es algo extraordinariamente complejo debido a las múltiples interacciones que el problema de la pobreza tiene con el resto de la realidad de los países y sus territorios.

\subsection{La necesidad de un plan estratégico general}

Lo que acabamos de decir sobre las políticas de lucha contra la pobreza es importante para el diseño de las políticas públicas. Porque no se trata de limitarse a un tipo de actuaciones meramente compensatorias o asistenciales en áreas atrasadas o deprimidas, o de mejorar la "focalización" de los grupos más desfavorecidos para asegurar que las políticas redistributivas les lleguen efectivamente. Se trata de articular estrategias que permitan a todo el país salir de su situación de atraso y avanzar por la vía de un desarrollo general.

Sólo si está garantizado ese marco general, evitaremos que la lucha contra la pobreza se convierta en un freno para el desarrollo global del país. Ni siquiera hay que contentarse con que los indicadores de pobreza mejoren en alguna medida, porque ello puede ser compatible con el mantenimiento de dinámicas que perpetúan el subdesarrollo.

En todo este proceso complejo es esencial implicar a cuantos grupos sociales sea posible. El desarrollo de un país es una tarea tan compleja y amplia que no puede encomendarse sólo a la responsabilidad del Estado. Concitar voluntades y coordinar esfuerzos es una clave importante en todo este proceso. Concretamente, es frecuente menospreciar la complicidad de los grandes productores, olvidando el peso específico que tienen en la economía y en la vida del país.

\subsection{La importancia del tejido institucional y de la gobernabilidad}

Pero por mucho que se logre implicar a todas las fuerzas sociales, el papel del sector público es, por muchas razones, insustituible.

Vaya por delante que el Estado tiene que superar el rol excluyente que asumió en otros tiempos como promotor único y tecnócrata del desarrollo. Su función es subsidiaria: ha de facilitar e impulsar las potencialidades y las dinámicas que proceden de todos los ámbitos del territorio.

Ante todo tiene que garantizar un marco de gobernabilidad a nivel nacional y local, con reglas del juego claramente definidas y con unas estructuras administrativas serias y fiables. Su presencia ha de hacerse notar en todo el territorio, más allá de las delegaciones ministeriales o de los servicios técnicos. 
Las escuelas, los centros de salud, los servicios básicos son manifestaciones de esta presencia por todo el territorio.

Resulta paradójico que algunos sigan propugnando una reducción del Estado, cuando en muchos países en desarrollo esta presencia es prácticamente inexistente. No sólo no debe reducirse, sino que debe aumentarse, en términos de recursos empleados (humanos y económicos) y en términos de eficiencia y racionalidad. Ello implica, entre otras cosas, una lucha sin cuartel contra la corrupción. No olvidemos que la corrupción constituye hoy en muchos países una amenaza, no sólo para cualquier evolución democrática y puesta en práctica de políticas adecuadas de lucha contra la pobreza, sino para la credibilidad misma de las administraciones públicas ante sus propios ciudadanos.

El avance en la institucionalidad a nivel del Estado y en la institucionalidad local debe acompañarse de la democratización de las instancias de participación ciudadana, del fortalecimiento y descentralización de órganos participativos de planificación nacional y de la consolidación del proceso de descentralización del Estado.

\subsection{Necesidad de estabilidad macroeconómica y crecimiento económico}

Como ya hemos comentado más arriba, no es posible el desarrollo sin un marco de estabilidad macroeconómica. No obstante, esta estabilidad no puede ser conseguida a cualquier precio y a través de un elevado coste en términos de equidad, de sostenibilidad e incluso de eficiencia.

Concretamente los costes humanos y ambientales de los programas de ajuste han sido tan elevados que es necesario revertir esa tendencia mediante un verdadero plan de desarrollo para los diferentes territorios. Más aún, en muchos países las políticas de estabilización han debilitado los mecanismos e instituciones públicas, tan necesarios para el desarrollo: también aquí hay que actuar en consecuencia. Y algo parecido ocurre con las restricciones macrofinancieras, necesarias en una primera fase del ajuste, pero difíciles de mantener si se quieren poner en práctica políticas de desarrollo a largo plazo.

Conviene también recordar que el crecimiento económico es sólo una condición necesaria para el desarrollo y la disminución de la pobreza, pero en absoluto suficiente. Cuando las desigualdades son grandes o los niveles de educación secundaria muy bajos entre la población adulta, es difícil confiar en el "efecto rebalse" del crecimiento económico como vía eficaz para acabar con la pobreza. 
3.8. El papel crucial de la demografía y las migraciones

Como se reconoce en el principio $8^{o}$ de la Agenda $21^{24}$ la existencia de políticas demográficas apropiadas es clave. Sin embargo, éstas no acaban de integrarse en las estrategias de desarrollo de los países empobrecidos.

Como en otros casos, también aquí los enfoques teóricos divergen ${ }^{25}$. Para unos las altas tasas de crecimiento demográfico son la causa de la pobreza ("son pobres porque son muchos"). En el extremo contrario, piensan otros que las altas tasas de crecimiento demográfico son la consecuencia de la pobreza ("son muchos porque son pobres"). Nosotros suscribiríamos una tercera posición, según la cual las altas tasas demográficas y la pobreza son manifestaciones del subdesarrollo que, a su vez, depende de muchos y muy complejos factores ("son muchos y pobres porque existe subdesarrollo").

En todo caso las diferencias en la demografía de los pueblos están estrechamente relacionadas con los movimientos migratorios, ya se trate de migraciones externas como de movimientos migratorios internos desde el campo a la ciudad.

La realidad de las migraciones externas no está recibiendo la atención que merece, y sólo es estudiada desde los países receptores de emigrantes, pero su impacto sobre los países de origen es enorme:

- Afecta a la unidad familiar al dividir a ésta (doble unidad familiar: en el país de origen y en el país receptor).

- Tiene como protagonistas a las personas con más iniciativa, con ciertos recursos, con decisión para emigrar, hasta con cierta formación (el capital humano en el que más se ha invertido es el que está migrando), mientras que los que se quedan en el país de origen es la gente de menos posibilidades, que son los menos capacitados para promover el desarrollo en su propio territorio.

- Supone importantes remesas de divisas, pero es muy dudoso que su impacto real sea positivo para el desarrollo de las localidades de origen.

Las migraciones interiores suelen ser consecuencia del fenómeno prácti-

24 "Para alcanzar el desarrollo sostenible y una mejor calidad de vida para todas las personas, los Estados deberían (...) fomentar políticas demográficas apropiadas”.

25 Especialmente significativos fueron los debates al respecto en las Conferencias Mundiales sobre Población y Desarrollo (sobre todo la de El Cairo). 
camente irreversible de la desagrarización que suministra mano de obra a los sectores secundario y terciario. Este proceso puede ser positivo, pero su efecto real dependerá de las nuevas condiciones de trabajo y de vida (asentamiento y vivienda) en las ciudades a las que emigra la población: no es igual dejar el campo para trabajar en la maquila y hacinarse en barrios marginales, que hacerlo para ocuparun empleo digno y disponerde unas condiciones materiales de vida relativamente decentes.

Desgraciadamente, por regla general, la disminución de la pobreza rural ha consistido simplemente en transformarla en pobreza y marginalidad urbanas: el remedio ha sido peor que la enfermedad. Pero también pueden citarse experiencias sumamente interesantes de co-desarrollo en algunos lugares de América Latina, que podrían ser imitadas en muchos países.

En resumen, las migraciones -sean interiores o exteriores-pueden representar una amenaza, pero también pueden generar oportunidades o incluso constituirse en fortaleza si se encauzan adecuadamente. Aprovechar positivamente estas tendencias migratorias es tanto más importante cuanto que estamos ante un fenómeno que a medio plazo indudablemente se mantendrá e incluso aumentará.

3.9. La necesidad de un enfoque sistémico y de una aproximación interdisciplinar

La complejidad de los procesos de desarrollo impone la necesidad de analizarlos desde un enfoque sistémico, lo que implica la consideración de la complejidad de la realidad y los procesos, las múltiples interacciones entre los problemas, potencialidades, actores, proyectos, territorios...

A menudo en el pasado el desarrollo ha sido un fenómeno exclusivamente estudiado desde las ciencias económicas y, en el caso del desarrollo rural, agronómicas. Por ello es necesario reafirmar que el desarrollo no es "competencia" o "campo de estudio" de una única disciplina.

Una consideración unidimensional del desarrollo lo reduce, como ocurre a menudo, a un hecho exclusivamente económico o productivo. Por el contrario, la nueva concepción del desarrollo requiere de la consideración en igual medida de los elementos sociales, culturales, políticos, antropológicos, territoriales... Por tanto, la incorporación de las ciencias sociales no económicas (política, sociología, antropología social, historia...) y su vinculación con las instrumentales (ingenierías agronómica, civil, industrial, geografía...) es un 
requisito indispensable para implementar estrategias efectivas en los programas nacionales, territoriales y locales de desarrollo.

Lo que se requiere, en el fondo, es, no sólo la conformación de equipos interdisciplinares, sino la "sociologización" de economistas e ingenieros y la "ingenierización o economización” de sociólogos y antropólogos.

3.10. Nuevos valores y actitudes en las organizaciones y en los técnicos: hacia una ética del desarrollo

Un componente esencial de lo que hoy en día se engloba bajo el concepto polifacético de "capital social"26 es la necesidad de adoptar un sistema de valores compartidos, expresión del deseo social de desarrollarse del país, tanto de sus líderes y responsables, como de sus técnicos e incluso de la propia población afectada; dicho con otras palabras, de asumir una ética del desarrollo.

Sin ninguna pretensión de exhaustividad, enumeramos a continuación algunos componentes de esa ética del desarrollo, como ejemplos de un sistema de valores compartidos sobre nuevas actitudes ante el desarrollo:

- No hay desarrollo si no existe en el país un auténtico "deseo social de desarrollarse”, asumido por la población y liderado por élites interesadas por el propio país. Es este un factor puesto de relieve con razón en los procesos de desarrollo económico de la Europa de la postguerra.

- Son los intereses generales los que han de orientar toda la actividad, evitando la subordinación de las actuaciones de desarrollo a meros intereses oligárquicos, egoístas, gremiales, localistas o incluso exclusivamente políticos, en sentido partidista: porque los intereses colectivos han de estar siempre por encima de los de personas o grupos. Naturalmente, un cierto grado de consenso sobre dichos intereses generales es indispensable para avanzar en la aventura del desarrollo.

- Aunque un cierto liderazgo es necesario, el desarrollo precisa de la participación de todos. La sociedad y los grupos que la componen no serán sólo sus beneficiarios, también sus protagonistas.

- Hay que evitar siempre el peligro de la tecnocracia, que sólo conduce a una percepción sesgada de la realidad desde el punto de vista exclusivo de los técnicos.

26 Cf. E. Moyano (2001), "El concepto de capital social y su utilidad para el análisis de las dinámicas del desarrollo", Revista de Fomento social, nº 221, enero- marzo, pp. 35-63. 
- El desarrollo como proceso implica también una nueva cultura, constituida por ciertos principios básicos del "buen hacer", que inspiren todas las relaciones contractuales (en sentido amplio). Por ejemplo: lo que se firma se cumple, los acuerdos se honran, los plazos acordados se respetan, etc.

Una "ética para el desarrollo" como la apuntada -y que requeriría una mayor explicitación-no puede limitarse a inspirar un plan de desarrollo, sino que ha de convertirse en un desafío para toda la sociedad afectada, involucrando a todas las personas e instituciones que pueden jugar un papel de liderazgo en valores (élites económicas, clase política, partidos, iglesias, organizaciones de la sociedad civil local, ONG, sistema educativo en todos sus grados, investigación, instituciones financieras, agencias internacionales etc.).

\section{Algunas responsabilidades del Norte}

El subdesarrollo del Surno es un problema exclusivo del Sur. Yno sería honesto concluir este texto sin aludir de forma explícita a las responsabilidades de los países desarrollados en relación con el hecho del subdesarrollo en el mundo. Tan importante es este tema que merecería otra reflexión monográfica...

Hemos de comenzarrecordando que hablamos desde el Norte rico. No podemos limitarnos a decir a los pueblos del Sur empobrecidos lo que ellos tienen que hacer. Tenemos que reconocer además nuestras propias responsabilidades. $Y$ tampoco podemos contentarnos, como parece ser la opinión pública dominante en nuestros países, pensando que lo único que a nosotros nos corresponde para afrontar esta cuestión es la cooperación al desarrollo, la ayuda.

Desde estos presupuestos vamos a hacer un breve recorrido para dejar constancia de nuestras responsabilidades en una serie de temas que, aunque están implícitos a lo largo del texto, se encuentran un tanto dispersos y conviene ahora explicitar.

- El desarrollo de los pueblos y todas las cuestiones relacionadas con él han de plantearse en la actualidad en el marco de la globalización. La globalización permite comprender mejor las dificultades y las oportunidades específicas del momento presente. Las dificultades provienen de que todo el proceso está siendo controlado por los actores y los intereses del Norte. Las oportunidades no faltan en un mundo tan interrelacionado, pero para ser aprovechadas por los países del Sur es preciso orientar todo el proceso, no como una "globalización excluyente", sino como una 
"globalización integradora"27. ¿Un sueño o una utopía? Como decíamos al concluir el texto editorial que acabamos de citar, “...no olvidemos que todas las grandes conquistas de la humanidad comenzaron siendo 'utopías' y encontraron el rechazo, cuando no el desprecio, de los más acomodados".

- La asunción no hipócrita de las metas del desarrollo sostenible lleva consigo un cuestionamiento bastante radical del modelo de desarrollo y de consumo de los países ricos del Norte. Como indicábamos más arriba, no hay desarrollo sostenible sin satisfacción de las necesidades básicas y con pobreza, ni hay verdadero desarrollo humano actual que ponga en peligro el desarrollo humano de las generaciones futuras. Es más, los grandes problemas de depredación medioambiental están mucho más asociados a la acumulación de capital y su manejo extensivo en los países ricos, que a la satisfacción de las necesidades básicas. Mucho queda por hacer en el Norte, y también en el Sur, para adoptar nuevos modos de consumo y producción limpios, conservadores y regeneradores del medio ambiente. Y ése será uno de los caminos de superación de la pobreza viables a largo plazo, aun reconociendo que supone un reto difícil a todos los niveles y que exige niveles mucho mayores de creatividad e innovación.

- El deterioro de los términos de intercambio y los problemas derivados del comercio internacional muestran fehacientemente que las reglas vigentes en el comercio internacional perjudican notablemente los intereses de los países del Sur. No basta con avanzar hacia una liberalización simétrica del comercio, porque ello sólo conducirá a una mayor dominación de los mercados por el Norte y sus productos. Ello es particularmente sangrante en los productos agrarios donde el proteccionismo de los grandes bloques, empezando por Estados Unidos y la Unión Europea, perjudica claramente las posibilidades exportadoras de los países agroexportadores del Sur.

- También en la liberalización de los movimientos de capital, consecuencia de la globalización financiera, se ha seguido el ritmo de los intereses del Norte, más capacitados para defenderse de la inestabilidad creciente de dichos mercados. En efecto, las crisis financieras resultantes, algunas de ellas relativamente recientes, han afectado espectacularmente a los

27 CONSEJO DE REDACCIÓN (2000), "Globalización integradora vs. globalización excluyente", Revista de Fomento social, nº 218, abril-junio, pp. 143-160. 
países del Sur, mucho más vulnerables ante los embates incontrolados e irracionales del mercado. Las medidas oportunas para protegerse de estos avatares financieros no pueden ignorar esta debilidad de unos frente a los otros ${ }^{28}$. Aunque la ausencia de fenómenos equivalentes en los años más recientes muestra que ya existe un control más estricto en estos mercados por parte de los países más desarrollados, no debe ocultarse que los mercados de valores se caracterizan por una gran volatilidad y que los mercados de divisas sufren los efectos desequilibradores procedentes de la economía americana y de la de algunos países asiáticos.

- Aludíamos al hecho migratorio como expresión de los grandes desequilibrios económicos Norte-Sur. También aquí la responsabilidad para los países ricos (que tanto se han aprovechado del trabajo de inmigrantes) es considerable, porque son ellos los que dictan las condiciones en que se realizan las migraciones externas, pensando sólo en su capacidad, limitada sin duda, para absorber inmigrantes ${ }^{29}$. Las políticas fuertemente restrictivas al uso deben ser acusadas de miopía porque ignoran lo que está en juego en los próximos años: la posibilidad de construir un orden mundial más justo y, no lo olvidemos, pacífico.

- Sin llegar a alinearse de forma acrítica con los más radicales movimientos llamados antiglobalización, es preciso cuestionar la presión que los países del Norte, en particular los bloques más poderosos, ejercen sobre los organismos internacionales (Banco Mundial, FMI, OMC). ¿No están demasiado condicionados por los intereses de los países que más influencia ejercen sobre ellos? ¿No están perdiendo la oportunidad de dar pasos para constituir un buen sistema de gobierno mundial, especialmente orientados a resolver los graves problemas planetarios (pobreza, desigualdad, agotamiento de los recursos, deterioro medioambiental, etc. etc.)? En ese sentido se impone democratizar estas instituciones de manera que estén representados efectivamente en ellos los intereses de todos y que funcionen al servicio de la mayoría de la población del mundo.

28 Precisamente nos referimos a este problema de forma detallada en un editorial anterior: Consejo de Redacción (1998), "La crisis financiera mundial”, Revista de Fomento Social, nº 212, octubre-diciembre, pp. 465-482.

29 Es un tema que nos llevaría muy lejos. Remitimos a nuestra reflexión editorial: CONSEJO DE REDACCIÓN (2001), "Migraciones y globalización: los derechos humanos como marco de referencia", Revista de Fomento Social, nº 224, octubre-diciembre, pp. 535-554. 
- Aunque no sea lo más importante, en ese contexto no podemos eludir una referencia a la responsabilidad que debe asumir el Norte mediante la cooperación internacional al desarrollo. No hemos querido convertir este texto en un trabajo sobre la cooperación ${ }^{30}$. Pero es mucho lo que queda por hacer para mejorar el sistema de ayuda y garantizar, tanto desde el punto de vista de la cantidad como sobre todo de la calidad, que dicho sistema constituya una palanca para co-operar al desarrollo de los países del Sur. En este ámbito, tan importante o más que el cuánto de la cooperación (¿cuándo se llegará al famoso 0,7\%?) es el cómo de la cooperación (hacer las cosas bien); y sobre todo el por qué de la cooperación. A este respecto no basta decir: "si se hace cooperación, hágase bien" (a ello se están dedicando esfuerzos y análisis cada vez más rigurosos); hay que decir más: "hay una obligación moral de hacer cooperación", como una forma de contrarrestar (de "restituir", dirían los moralistas clásicos) lo que se ha expoliado de una forma directa o indirecta en épocas pasadas.

- Tampoco es desdeñable la responsabilidad de las empresas, yen particular las empresas multinacionales. Existe el peligro, sobre todo en la opinión pública, de pensar que sólo a los gobiernos toca afrontar los retos de la pobrezay desigualdad, ya que las empresas, porsu propia definición, "están para ganar dinero". Pero el impacto y la influencia de las empresas en la sociedad es enorme: no sólo producen bienes y servicios para satisfacer las necesidades humanas y sociales y generan la renta que todos necesitamos para vivir (sus funciones propias); además influyen sobre nuestros gustos, moldean nuestros hábitos de conducta y la forma de organizar la vida, condicionan el entorno social en que se localizan, producen efectos sobre el medio ambiente que nos envuelve, ejercen su acción sobre los gobiernos y hasta sobre los organismos internacionales. Por eso es de enorme relevancia la actual tendencia a exigir a las empresas el cumplimiento de su responsabilidad social; se trata, desde luego, de un imperativo ético, pero sobre todo de una condición de supervivencia ${ }^{31}$.

30 Véase Consejo de RedAcción (1994), "Las dos batallas del 0,7\%: solidaridad y desarrollo", Revista de Fomento Social, nº 196, octubre-diciembre, pp. 477-492. Sus reflexiones siguen vigentes.

31 Véanse, por ejemplo: I. CAMACHo LARAÑA (2004), "La responsabilidad social de la empresa: un proceso abierto", Revista de Fomento Social, no 233, enero-marzo, pp. 75-98; R. A. ARAQUE PADILLA (2004), "Factores condicionantes de la responsabilidad social de la empresa: los límites de lo posible", Revista de Fomento Social, nº 235, julio-septiembre, pp. 553-592. 


\section{A modo de conclusión}

Al concluir el presente texto y releer nuestras propias reflexiones queda siempre una cierta sensación de frustración derivada de la magnitud y profundidad del problema abordado (la pobreza y la desigualdad mundiales), de la magnitud del reto planteado (luchar contra ellas de muy diversas maneras) o de la diversidad enorme de contextos y situaciones reales (ante los que hay que modular cualquier planteamiento teórico previo para adaptarlo a cada realidad).

Pero lo más preocupante es la impresión permanente de que falta voluntad política en quienes tienen mayor poder de actuación. Las soluciones, cuando llegan, llegan tarde, y suelen ser escasas y hasta cicateras, lo mínimo para que no estallen situaciones incontrolables.

Nuestro mundo, sobre todo el del Norte desarrollado, parece dominado por la inercia de un crecimiento económico que no tiene otro horizonte que el de un bienestar basado en el consumo, bajo la amenaza además de un marco globalizador que exige considerables esfuerzos por ser competitivos. ¿Hay lugar en tal escenario para las ideas que hemos barajado en este editorial?

Creemos que sí, y prueba de ello es que estas ideas son objeto de debate y que surgen nuevos planteamientos y alternativas. A este debate han querido contribuir estas páginas aclarando y ordenando ideas, aportando experiencias, provocando la pregunta ética. 